\title{
Effects Of Goat Milk Peptide On Immuno Histo Chemistry Profile Of Lung Cancer Rattus Norvegicus
}

\author{
Romziah Sidik ${ }^{1}$ and Aulanni'am Aulani'am². \\ ${ }^{1}$ Professor in Animal Husbandry Department, Faculty of Veterinary Medicine, \\ UniversitasAirlangga, Indonesia (romez02@yahoo.com). \\ ${ }^{2}$ Professor in Biochemistry Department Faculty of Veterinary Medicine, Brawijaya University, \\ Indonesia(aulani@brawijaya.ac.id)
}

\begin{abstract}
Complete feed with high linoleic acid content may produce goat milk containing high linoleic acid too and it has specific protein with molecular weight of $42 \mathrm{kDa}$. The isolated milk peptide belong to goat milk containing 3.21\% Linoleic acid (F2) and $4.80 \%$ (F3) can be promoted as candidate peptide with anti-carcinogenic effect. Twelfth male rats strain Rattusnorvegicusused as the experimental animals with average age about two months old, and body weight around 160 to 200g. The animals were divided into four groups: F0 a healthy rat as a control group. Group F1 rat with artificial lung cancer without goat milk peptide treatment, group F2 rats with artificial lung cancer treated by goat milk peptide (Pep-2) orally. Group F3 rats with artificial lung cancer treated by goat milk peptide (Pep-3) orally. Rattus novergicus in group F1, F2, and F3 were induced by Benzapirine, and incubated for 4 weeks. It was continued to treated with and or without milk peptide as well as the treatment group for one week period. The research was tailored into Complete Randomized Design. The immunohistochemistry expression be scored into apoptosis cell marker perform. Data was analyzed by SPSS software version 13.00.

Results of the research showed a significant $(\mathrm{P}<0.05)$ good recovery of their lung cancer of rat tissues being to normally in group F2 and F3. By immunohistochemistry technique using antibody Apoptag and DAB substrate, it were performed that alveoli of bronchi septum be compactly, no infiltration of inflammation cell any more, again to form the long bronchi connective tissue and apoptotic cell well performed. However, by continuing treatment by goat milk peptide orally, it be expected an increasing of apoptosis expression rate.
\end{abstract}

Key word: goat milk peptide, linoleic acid, lung cancer, immunohistochemistry, rat.

\section{INTRODUCTION}

The source of bioactive milk protein in goat consisted of peptide and casein which are released by proteolytic process. The major proportion of goat milk protein is casein about $80 \%$, include $\alpha, \beta$ and k-caseins. Proportion of whey protein of goat milk about $20 \%$, and its containing $\alpha$-lactalbumin, lactoferin, immunoglobulins ( $\operatorname{IgA}, \operatorname{IgM}, \operatorname{IgG}$ ), albumin serum and lysosome. The goat milk protein content was higher compared to human and cow milk, the extreme differences with human whey protein is no $\beta$-lactoglobulin obtained in human milk, however, it was higher in goat milk whey protein (Tay and Gam, 2011). Therefore, goat milk recommended for consumed by human who have allergic with cow milk. Bioactivities of goat 
milk peptide due to maintain physiology function of the body systems, like in the cardiovascular, digestive, immune and nervous systems (Haque, et al., 2017), also it beneficial for promote the health condition, as an antioxidant, immunomudolatory, and some therapeutic effects as well as antimicrobial, antihypertensive, and antithrombotic (Atanasova and Ivanova, 2010). The bioactive of peptide yield depend on the protein content in milk and species. Other essential nutrient in milk is Conjugated Linoleic acid (CLA) is an essential unsaturated long chain fatty acid in ruminant milk, and it potential as anti-inflammation and anti-carcinogenic in human and animals. CLA (C-9, c-12 C18:2 linoleic acid) with double bonds of carbon positions varies depends on animal species, the quality and intake of diet by dairy ruminant animals (Haug et. al., 2007).

The aim of the research is to observe of the effects of isolates goat milk peptide with high Linoleic acid content as an antioxidant and anticancer on lung cancer rat.

\section{MATERIAL AND METHOD}

Two types of isolates goat milk peptide, namely: Pep-2 is isolated milk peptide from goat milk containing $3.21 \%$ Linoleic acid, and Pep-3 isolated goat milk peptide with $4.80 \%$ linoleic acid content that promoted as candidate peptide with anti-carcinogenic effects, with specific molecular weigh $42 \mathrm{kDA}$ (Romziah et al., 2012). The isolation of goat milk peptide used electroelution technique. Gel contained protein tape were sliced into small form, then added by selofan plus Buffer Phosphate 0.2 M, and put in the electro-elution chamber which containing Buffer Phosphate $0.1 \mathrm{M}$, the elution process for over night in electricity condition at $250 \mathrm{~V}$ and $20 \mathrm{~mA}$ plus with the cold selofan, vortex. It incubated at $4^{0} \mathrm{C}$ about $4-5$ minutes, then continued by centrifugation at $10000 \mathrm{rpm}$ for 15 minutes. The precipitate were dried with air flow, and then added with 100 micro liter Buffer Tris $\mathrm{Cl}$, and were kept in $-20^{\circ} \mathrm{C}$.

Twelfth male rats strain Rattus norvegicus used as the experimental animals with average age about two months old, and body weight around 160 to $200 \mathrm{~g}$. Three rats were kept in healthy without induced by benzaphirine and be used as control group. The other nine rats were induced by benzaphirine with dose $200 \mathrm{mg} / \mathrm{kg}$ body weight during four days with interval of inducing ones a day, then it were incubated during 4 weeks. All rats received concentrate pellet as a basal diet wit ad libitum of drinker water. The experimental animals were divided into four groups: F0 a healthy rat as a control group. Group F1 the rats with artificial lung cancer without goat milk peptide treatment, group F2 rats with artificial lung cancer treated by goat milk peptide type Pep2 with the dose 200 micro litter/hd/d by orally for one week period. Group F3 rats with artificial lung cancer treated by goat milk peptide type Pep-3 by orally with the dose $200 \mathrm{micro}$ litter/hd/d for one week. After completely induced by benzaphirine, both rats in group F2 and F3 were incubated during one week. At the end of the research, all experimental rats were euthanized, and necropsy to observe the lung by immunohistochemical technique. Expression of Apoptag (apoptotic marker) in histological samples evaluated by semi-quantitative method using Remmele modified method (Kaemmere et al., 2012). Indext Remmele Score (IRS) constituted of multiply percentage of immune-reactive score with intensity of marker yield in cell. The research was tailored into Complete Randomized Design (4 treatments x 3 replications). The immunohistochemistry expression be scored into apoptosis cell marker perform. Data was analyzed by SPSS software version 13.00. 


\section{RESULTS AND DISCUSSION}

\begin{tabular}{|l|l|}
\hline $\begin{array}{l}\text { Figure 1. The healthy lung of rat in group F0 (100xenlarger). } \\
\text { Expression of immunohystochemistry using Apoptag antibody } \\
\text { and DAB substrate showed the apoptosis cell with brown color } \\
\text { (see the yellow arrow). }\end{array}$ & $\begin{array}{l}\text { Figure 2. The lung cancer of rat in group F1 (100xenlarger). } \\
\text { and DAB substrate showed the number of apoptosis cell with } \\
\text { brown color is lower compared to normal lung (see the yellow } \\
\text { arrow). }\end{array}$ \\
\hline
\end{tabular}

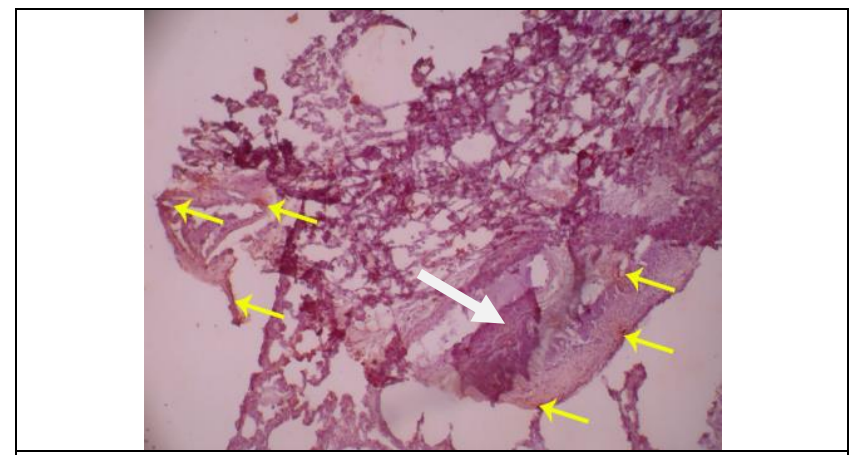

Figure 3. The lung cancer of rat in group F2 with milk peptide Pep-2 therapy (100xenlarger).

Expression of immunohystochemistry using Apoptag antibody and DAB substrate also showed the rate of apoptosis cell process with brown color is decrease compared to normal lung of rat (see the yellow arrow). However, the process of apoptosis will increase by milk peptide treatment.

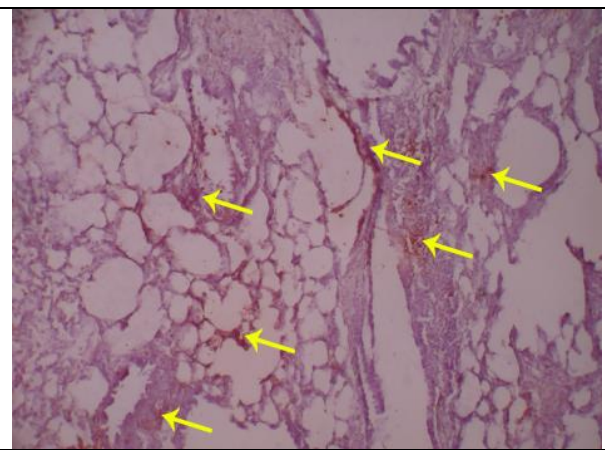

Figure 4. The lung cancer of rat in group F3 with milk peptide Pep-3 therapy (100xenlarger). .

Expression of immunohystochemistry using Apoptag antibody and DAB substrate also showed the rate of apoptosis cell process with brown color is decrease compared to normal lung of rat (see the yellow arrow). However, the process of apoptosis will increase by milk peptide treatment.

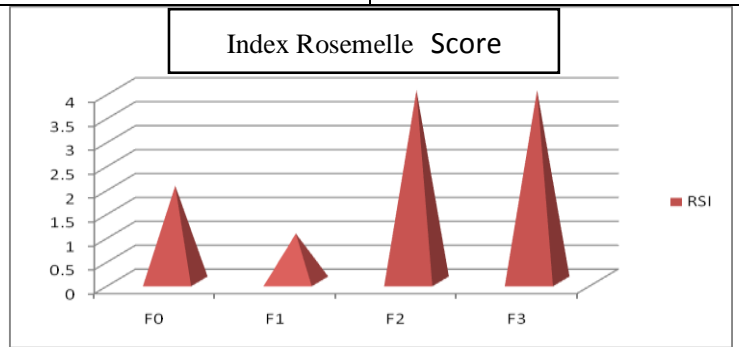

Figure 5. Profile of Remmele Score Index (IRS) of health lung rat (F0), lung cancer rat (F1), lung cancer with milk peptide Pep-2 therapy (F2), and lung cancer with milk peptide Pep-3 therapy (F3)

Figure 1 showed the profile of healthy lung rat in group F0, and Figure 2 showed the profile of lung cancer rat without milk peptide therapy in group F1. Figure 3 showed the lung cancer rat with milk peptide Pep-2 therapy, and Figure F4 showed the lung cancer rat with milk peptide Pep-3 therapy. Based on these figure, there were any differences $(\mathrm{P}<0.5)$ on apoptosis process 
among the treatments group. In the normal or healthy lung (Figure 1) of rat, the apoptosis process was normally done, it showed empty space in alveoli which is filled with air. In the lung cancer rat without any milk peptide therapy, it looked that rate of apoptosis process very slow, this is because of many alveoli cell of lung were damaged and cancer cell very faster developed (Figure2). Based on histological observation in lung cancer without milk peptide treatments tend being damaged on inter-alveolar septum structure with infiltration of inflammation cell inside. However, by given milk peptide Pe-2 and Pep-3 be expected that lung cancer be repaired the damage cell and increasing the apoptotic process. Lung cancer of rats with milk peptide therapy Pep-2 and Pep-3 showed any repaired of lung parenchyma structure, it prove by a new building of inter-alveolar septum, open space of lung alveoli, and any new connective tissue builder, that is manifest improving un perfect tissue or connective tissue mass replaced the lung parenchyma (see white arrow in Figure 3). Results on the observation on Index Remmele Score (IRS) among treatments group showed, the group of rats lung cancer with therapy milk peptide Pep-2 (F2) and therapy with milk peptide Pep-3 (F3) were no significantly $(\mathrm{P}>0.05)$ different and higher $(\mathrm{P}<0.05)$ compared to healthy lung rat $(\mathrm{F} 0)$ and lung cancer rat without therapy with milk peptide $(\mathrm{F} 1)$. The lower $(\mathrm{p}<0.05)$ IRS score found in group lung cancer rat without milk peptide therapy (F1), because the rate of apoptotic process declined. Hence, by given milk peptide therapy be expected to increased the rate of apoptotic process be increased. The IRS score in each group, namely: 2, 1, 4, 4 in F0, F1, F2, and F3, respectively

\section{CONCLUSION}

It was concluded that goat milk peptide can be used as the immune modulator to depress of cancer cell development, repaired of damaged inter-alveolar cell, increasing the Index Remelle Score on the rate of apoptotic process.

\section{REFERENCES}

Atanasova, J. and Ivanova, I. 2010. Antibacterial Peptides From Goat and sheep milk proteins. Biotechnol \& Biotechnol. EQ. PP.1799-1803.P

Kaemmerer D., Peter L., Lupp A., Schulz S., Sänger J., Baum R. P., Prasad V., Hommann M. 2012. Comparing of IRS and Her2 as immunohistochemical scoring schemes in gastroenteropancreatic neuroendocrine tumors. Int J Clin Exp Pathol 2012;5(3):187-194.

Romziah, S., Anwar, M., Retno, S.W. 2012. Milk peptide mapping of good fed complete feed with high linoleic acid content. Lucran Stiintifie - vol. 55, Seria Zootechnie. pp.252-256.

Tay, E.P. and Gam, L.H. 2011. Proteomic of human and the domestic bovine and caprine milk. As.Pac. J.Mol. Biol.. Biothechnol volo. 19. (1) . pp. 45-57. 